\title{
Differential hemispheric activation and handedness and hysterical and obsessive personality styles
}

\author{
DEBRA DUNIVIN and ROBERT ZENHAUSERN \\ St. John's University, Jamaica, New York 11439
}

\begin{abstract}
The relationship between a trait measure of differential hemispheric activation and obsessive and hysterical personality styles was determined. Significant correlations were found between the right activators and the hysterical scale and between left activators and the obsessive scale. Individual and familial sinistrality attenuated the correlations.
\end{abstract}

There is growing evidence for the existence of an individual difference variable based on the more or less consistent tendency to activate one cerebral hemisphere more than the other (see Gur \& Gur, 1980, for a recent review). Historically, lateral eye movements have been used as the indicator of cerebral activation under the assumption that the eyes move contralaterally to the activated hemisphere. Bakan (1969) and Day (1964, 1967) were the first to consider lateral eye movements indicative of relatively enduring personality and cognitive styles. At the same time, Kocel, Galin, Ornstein, and Merrin (1972), for example, provided evidence that lateral eye movements reflected question content, so that a logical or linguistic question, activating the left hemisphere, led to rightward eye movements, and a visual or spatial question, activating the right hemisphere, led to leftward eye movements. Gur, Gur, and Harris (1975) showed that both these positions were in fact correct and the direction of eye movements depended on both question content and on the conditions under which the questions were asked. In confrontation face-to-face situations, eye movements tended to reflect an individual difference variable, whereas in presumably less anxious non-face-to-face situations, eye movements were related to question type. Further evidence for this individual difference variable has been found using EEG (Furst, 1976) and brain blood flow (Gur \& Revich, 1980).

Based on evidence that the hemisphere more specialized for a task was not always the one that was activated for that task, Levy and Trevarthan (1976) postulated the existence of a theoretical metacontrol system responsible for mediating activation of the hemispheres. Within this framework, differential hemispheric activation may be considered a more or less consistent bias of the metacontrol system.

There has been preliminary work relating personality characteristics to differential hemispheric activation (see Gur \& Gur, 1980), but the most specific study has

Send correspondence to Robert Zenhausern, Psychology Department, St. John's University, Jamaica, New York 11439. been done by Smokler and Shevrin (1979). Based on a theoretical and intuitive comparison of the characteristics of hysterics and obsessive compulsives with the functions of the left and right hemispheres, they hypothesized and found that normal subjects with hysterical personality style tended to activate the right hemisphere and that normal subjects who showed an obsessive personality style tended to activate the left hemisphere. Lateral eye movements were used as the measure of hemispheric activation.

There are two problems associated with the use of lateral eye movements: one theoretical and one practical. The technique is a state measure, although Ehrlichman and Weinberger (1978), who do not feel that it is related to cognitive style, conclude in their review that there is a fair degree of intrasubject consistency. The state nature of lateral eye movements can be seen in the work of Tucker, Roth, Arneson, and Buckingham (1977), who found that increases in stress resulted in an increase of leftward movements. The more practical consideration is the time and effort necessary to screen right and left activators.

Zenhausern (Note 1) has developed a paper-and-pencil test based on "Your Style of Learning and Thinking" (Torrance, Reynolds, Riegel, \& Ball, 1978) that has successfully differentiated right and left activators in thinking style (Zenhausern, Note 1), information processing (Coleman \& Zenhausern, 1979), maze learning (Zenhausern \& Nickel, 1979), and the perception of emotion (Zenhausern, Notaro, Grosso, \& Schiano, in press). ${ }^{1}$ The purpose of this paper is to replicate the findings of Smokler and Shevrin (1979) using this groupadministered trait measure of hemispheric preference.

\section{METHOD}

\section{Subjects}

The subjects in this study were 49 male and 248 female undergraduates at a small Southern college. Based on self-report, 162 were right-handed with no familial sinistrality (mother, father, brother, or sister), 93 were right-handed with familial sinistrality, and 42 were left-handed. 
Table 1

Correlations Between Right and Left Preference Scores and Obsessive and Hysterical Scores for All Subjects

\begin{tabular}{|c|c|c|c|c|c|c|c|c|c|c|c|c|c|c|c|c|c|c|c|c|}
\hline & \multicolumn{5}{|c|}{ All Subjects } & \multicolumn{5}{|c|}{ RH/FS- } & \multicolumn{5}{|c|}{ RH/FS+ } & \multicolumn{5}{|c|}{ LH } \\
\hline & \multicolumn{2}{|c|}{ Obsessive } & \multicolumn{2}{|c|}{ Hysterical } & \multirow[b]{2}{*}{$\mathrm{N}$} & \multicolumn{2}{|c|}{ Obsessive } & \multicolumn{2}{|c|}{ Hysterical } & \multirow[b]{2}{*}{$\mathbf{N}$} & \multicolumn{2}{|c|}{ Obsessive } & \multicolumn{2}{|c|}{ Hysterical } & \multirow[b]{2}{*}{$\mathbf{N}$} & \multicolumn{4}{|c|}{ Obsessive Hysterical } & \multirow[b]{2}{*}{$\mathrm{N}$} \\
\hline & RPS & LPS & RPS & LPS & & RPS & LPS & RPS & LPS & & RPS & LPS & RPS & LPS & & RPS & LPS & RPS & LPS & \\
\hline Females & $.15^{*}$ & $.32 \dagger$ & $.12 *$ & -.08 & 248 & .14 & $.42 \dagger$ & $.18^{*}$ & -.03 & 135 & .15 & $.36 \dagger$ & .07 & -.15 & 76 & .18 & .01 & .05 & .20 & 37 \\
\hline Males & .06 & .16 & .16 & .25 & 49 & .09 & .27 & .09 & .07 & 27 & -.03 & .20 & .44 & .44 & 17 & & & & & 5 \\
\hline All Subjects & .09 & $.28+$ & $.15^{*}$ & .03 & 297 & .00 & $.38 \dagger$ & $.19 *$ & .11 & 162 & .10 & $.33 \dagger$ & .12 & .00 & 93 & .20 & .00 & .06 & .22 & 42 \\
\hline
\end{tabular}

Note $-R P S=$ right preference score, $L P S=$ left preference score $; F S-=$ no familial sinistrality, FS+ = familial sinistrality $;$ RH $=$ right handed, $L F=$ left-handed. Blank entries indicate insufficient $N . \quad{ }^{*} p<.05 . \quad \dagger_{p}<.01$.

\section{Materials and Procedure}

Preference questionnaire. Differences in consistent hemispheric activation was measured by a questionnaire that has shown consistency and construct validity when used as a gross screening instrument. The subjects rate themselves from 1 to 10 on 26 questions, 15 of which are scored right and 11 of which are scored left. Good differentiation has been obtained by selecting those subjects who score in the upper half of all subjects whose average right score is higher than the left or whose average left score is higher than the right. The trait nature of the scale can be seen from the questions asked. For example: "How good is your sense of direction?" "How well do you do crossword puzzles?"

Personality questionnaire. Hysterical and obsessive-compulsive personalities were measured by a questionnaire developed by Lazare, Klerman, and Armor (1966). Measures of the traits describing hysterical, obsessive, and oral personality types were condensed by factor analysis and revised to a 60 -item true-false test. Validity was based on the construct validity of the factor analysis. Split-half reliability ranged from .56 to .78 .

\section{Procedure}

All questionnaires were administered in small classrooms of from 20 to 30 subjects.

\section{RESULTS AND DISCUSSION}

The correlations between the right and left preference scores for all subjects and separately for right-handers, right-handers with and without familial sinistrality, and left-handers can be seen in Table 1. The expected relationships between the obsessive and left preference score and between the hysteric and right preference score was found for all females, especially those with no familial sinistrality. For those with familial sinistrality, the former correlation was reduced and the latter was no longer significant. There were no significant relationships for left-handers. The pattern of correlations for the males was similar but did not reach significance because of the small number of cases. When all subjects were combined, there was a consistent positive relationship between the left score of the preference test and the obsessive scale of the personality test that was significant for all groups except the left-handers. In addition, there is some evidence of attenuation of this correlation for right-handers with familial sinistrality. The correlations between the right preference score and the hysterical scale were somewhat lower and significant only for all subjects combined, all right-handers, and right-handers with no familial sinistrality.
These results replicate those of Smokler and Shevrin (1979) using a trait measure of differential hemispheric activation. The size of the correlation, however, should make it clear that individual differences in activating one hemisphere in preference to the other is but one factor in the development of the hysterical and obsessive personality styles. It may or it may not be a necessary condition.

The disappearance of the relationship between hemispheric preference and personality as a function of left-handedness is intriguing, but speculation without replication and refinement would be premature. An extension of this investigation to the neurotic extremes of these personality styles might provide answers as to the importance of left-handedness and differential hemispheric activation.

\section{REFERENCE NOTE}

1. Zenhausern, R. A comparison of two measures of cerebral dominance. Paper presented at the annual convention of the Eastern Psychological Association, Philadelphia, 1979.

\section{REFERENCES}

BAKan, P. Hypnotizability, laterality of eye movement and functional brain assymetry. Perceptual and Motor Skills, 1969, 28, 927-932.

Coleman, S., \& Zenhausern, R. Processing speed, laterality patterns and memory encoding as a function of hemispheric dominance. Bulletin of the Psychonomic Society, 1979, 14, 357-360.

DAY, M. An eye-movement phenomenon relating to attention, thought, and anxiety. Perceptual and Motor Skills, 1964, 19, 443-446.

DAY, M. An eye-movement indicator of type and level of anxiety. Some clinical observations. Journal of Clinical Psychology, $1967,23,443-446$.

Ehrlichman, H., \& Weinberger, A. Lateral eye movements and hemispheric asymmetry. A critical review. Psychological Bulletin, 1978, 85, 1080-1101.

Furst, C. EEG asymmetry and visuospatial performance. Nature, 1976, 260, 254-255.

Gur, R. C., \& Gur, R. E. Handedness and individual differences in hemispheric activation. In J. Herron (Ed.), Neuropsychology of left-handedness. New York: Academic Press, 1980.

Gur, R. C., \& Revich, M. Cognitive task effects on hemispheric blood flow in humans: Evidence for individual differences in hemispheric activation. Brain and Language, 1980, 9, 78-92.

Gur, R. E., Gur, R. C., \& Harris, L. Cerebral activation, as measured by subjects' lateral eye movements, is influenced by experimenter location. Neuropsychologia, 1975, 13, 35-44. 
Kocel, K., Galin, D., Ornstein, R., \& Merrin, E. Lateral eye movements and cognitive mode. Psychonomic Science, $1972,27,223-224$.

Lazare, A., Klerman, G., \& Armor, D. Oral, obsessive, and hysterical personality patterns. Archives of General Psychiatry, $1966,14,624-630$.

Levy, J., \& Trevarthan, C. Metacontrol of hemispheric function in human split-brain patients. Journal of Experimental Psychology: Human Perception and Performance, 1976, 2, 229-312.

Smokler, I., \& Shevrin, H. Cerebral lateralization and personality style. Archives of General Psychiatry, 1979, 36, 949-954.

Torrance, E., Reynolds, C., Riegel, T., \& Ball, O. Revised norms-Technical manual for Your Style of Learning and Thinking. Athens: University of Georgia, 1978.

Tucker, D., Roth, R., Arneson, B., \& Buckingham, V.
Right hemisphere activation during stress. Neuropsychologia $1977,15,697-700$.

ZENHAUSERN, R., \& NiCKel, L. Hemispheric dominance and maze learning. Bulletin of the Psychonomic Society, 1979, 14, 435-436.

Zenhausern, R., Notaro, J., Grosso, J., \& Schiano, P. The interaction of hemispheric preference, laterality, and sex in the perception of emotional tone and verbal content. International Journal of Neuroscience, in press.

\section{NOTE}

1. Copies of the questionnaire and preliminary norms are available from Robert Zenhausern on request.

(Received for publication December15, 1980.) 